East African Medical Journal Vol. 77 No. 6 June 2000

CA 15-3, CERULOPLASMIN AND TISSUE POLYPEPTIDE SPECIFIC ANTIGEN AS A TUMOUR MARKER PANEL IN BREAST CANCER

Ö. Özyilkan, MD, Associate Professor, Bayindir Hospital, Department of Medical Oncology, Ankara, Turkey, E. Baltali, MD, Professor, and S. Kirazli, Medical Laboratory

Technician, Hacettepe University Institute of Oncology, Ankara, Turkey.

Request for reprints to: Dr. Ö. Özyilkan, Çelik sitesi B blok, 42, sokak 64/13, Yukari Dikmen Mah., Oran, TR 06450, Ankara, Turkey.

\title{
CA 15-3, CERULOPLASMIN AND TISSUE POLYPEPTIDE SPECIFIC ANTIGEN AS A TUMOUR MARKER PANEL IN BREAST CANCER
}

\author{
Ö. ÖZYILKAN, E. BALTALI and S. KIRAZLI
}

\begin{abstract}
Background: Tumour markers along with other tests, may be useful in the assessment of the prognosis, monitoring response to treatment and early detection of metastases in breast cancer. The most commonly used breast cancer antigen is CA 15-3.

Objective: To examine the value of CA 15-3, ceruloplasmin and tissue polypeptide specific antigen (TPS) panel in the monitoring of breast cancer.

Subjects: Serum concentrations of CA 15-3, ceruloplasmin and TPS were measured in 90 women: Fifteen controls, sixteen patients with benign breast disease (BBD), thirty one patients in remission and twenty eight patients with active breast cancer.

Results: The results of CA 15-3, ceruloplasmin and TPS estimates were separated into four groups. The patients not in remission were found to have significantly higher levels of CA 15-3 $(p<0.0001)$ and ceruloplasmin $(\mathbf{p}<0.0001)$ compared with the other three groups. The difference between the patients in remission, $B B D$ and the control group was not statistically significant ( $p>0.05)$ for CA 15-3 and ceruloplasmin. The difference for TPS between the patients in remission and the patients with active breast cancer was not statistically significant ( $p>0.05)$. The sensitivities of CA 15-3, ceruloplasmin, and TPS for detecting active breast cancer were $75.0 \%, 75.0 \%$, and 78.0\%, respectively.

Conclusion: The highest sensitivity for active breast cancer detection was obtained by the combined use of three tumour markers. We concluded that there may be an advantage in using panels in the follow up of breast cancer patients, although so far such tests have too low a specificity to be of practical value in screening.
\end{abstract}

\section{INTRODUCTION}

As understanding of the pathophysiology of cancer increases, the role of tumour markers becomes more important in the management of cancer patients. Classically, such markers are synthesised by tumour cells and released into the circulation but they may also be produced by normal tissues in response to invasion by cancer cells $(1,2)$. These markers may include a variety of enzymes, hormones and antigens but, to-date, most have been used in conjunction with other tests for determining the disease state, response to surgery, chemotherapy and radiation therapy $(2,3)$. The most recently discovered breast cancer antigen CA 15-3, a serum muci-glycoprotein, has been identified by reaction with two monoclonal antibodies(4,5). Clinical studies indicated a good correlation between CA 15-3 and breast cancer(5,6).

Serum ceruloplasmin has been reported to be a useful marker of disease activity in patients with carcinoma of the breast, lung, gastrointestinal tract, acute leukaemias and Hodgkin's and non-Hodgkin's lymphomas(7-10).
The possible role of ceruloplasmin in oncogenesis is not clear, but, it has been suggested that it may be involved in angiogenesis and neovascularisation at the site of tumour growth. Breast cancer cell lines have been found to contain ceruloplasmin mRNA whilst normal breast cells do not express this gene(6). Tissue polypeptide specific antigen (TPS) is a polypeptide marker and high TPS serum levels appear to reflect increased cell proliferative activity. Elevated concentrations of TPS have been detected in association with a wide variety of malignancies, including breast cancer(11-13).

In this study, we assessed the individual and combined value of CA 15-3, ceruloplasmin, and TPS measurement in patients with benign and malignant breast diseases.

\section{MATERIALS AND METHODS}

This study included 16 female patients with benign breast disease (BBD), 59 female patients with histologically documented carcinoma of the breast and 15 healthy female volunteers. All the patients were from the Division of Medical Oncology at the Hacettepe University Hospital. The control group of healthy 
females was clinically negative for breast disease. Their median age was 36 years (range 18-56 years). The histological examination of the BBD revealed seven fibrocystic disease, eight fibroadenoma and one papilloma. The median age of this group was 31.5 years (range 17-45 years). The median age of the breast cancer patients was 45 years (range 27-70 years) and 28 out of 59 patients with breast cancer had metastatic disease or relapse while the remaining 31 were in remission. Twelve of the 15 patients in remission were on adjuvant therapy (chemo- or hormonal) at the time of this study following a radical or modified radical mastectomy with or without radiotherapy.

None of the patients or healthy volunteers had laboratory or clinically proven evidence of infection, primary inflammatory disease, thyrotoxicosis, pregnancy, cirrhosis or proteinuria when blood samples were collected. Serum ceruloplasmin and $\mathrm{C}$-reactive protein (CRP) were measured using a radial immunodiffusion technique (Binding Site, UK), CA 15-3 levels by an immunoradiometric assay technique (Centocor IRMA), and TPS levels by a TPS-ELISA kit (Beki Diagnostics, Bromma, Sweden).

Difference of the means between the groups were analysed by one-way ANOVA and Kruskall-Wallis tests. The relationships between the markers were analysed using linear regression analysis.

\section{RESULTS}

The results of the CA 15-3, ceruloplasmin, and TPS were separated into four groups: healthy volunteers, patients with BBD, breast cancer patients in remission and breast cancer patients not in remission as shown in Figures 1-3.

\section{Figure 1}

Distribution of serum CA 15-3 levels in patients with active breast cancer (relapse or metastases), breast cancer in remission, benign breast disorders, and a control group

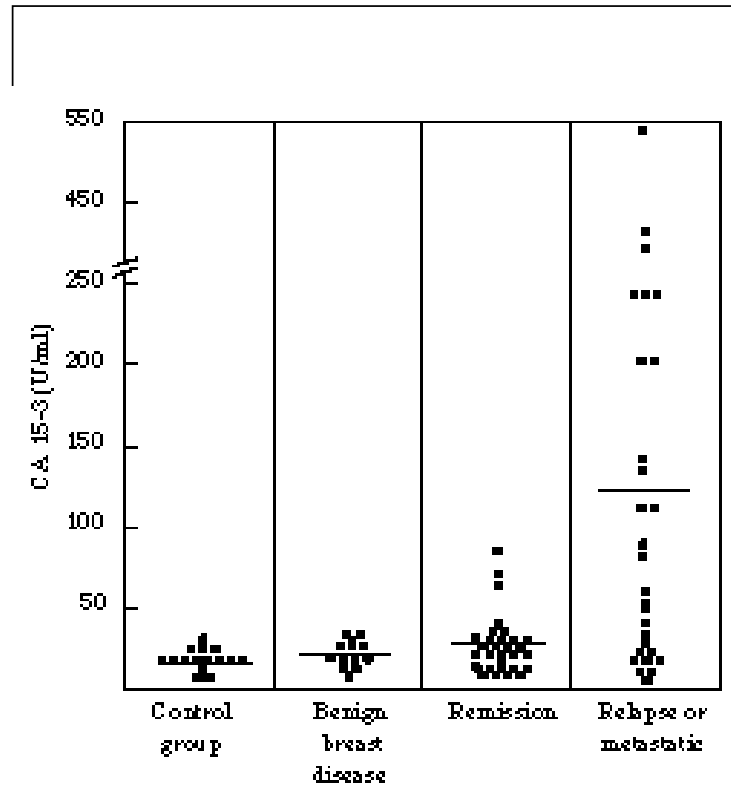

Figure 2

Distribution of serum ceruloplasmin levels in patients with active breast cancer (Relapse or metastases), breast cancer in remission, benign breast disorders, and a control group

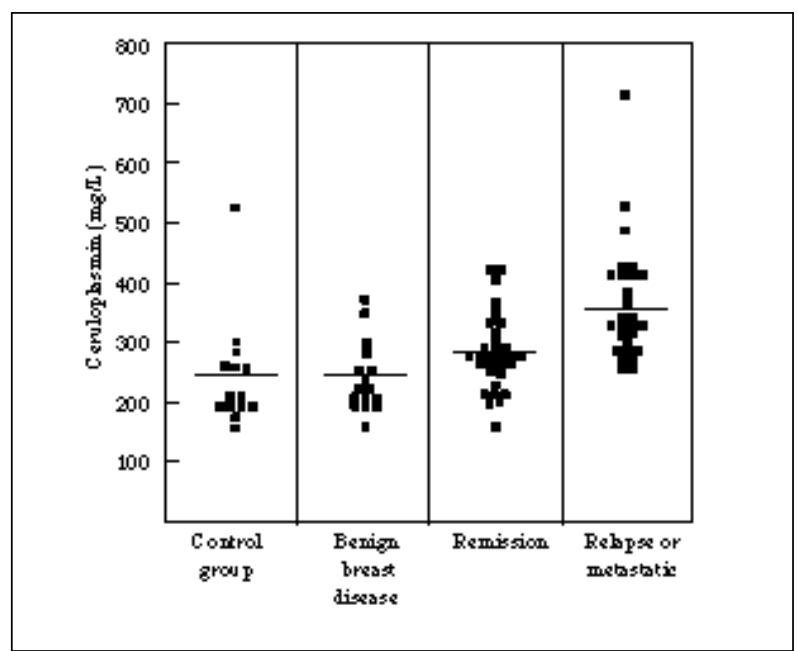

Figure 3

Distribution of serum TPS levels in patients with active breast cancer (relapse or metastases), breast cancer in remission, benign breast disorders, and a control group

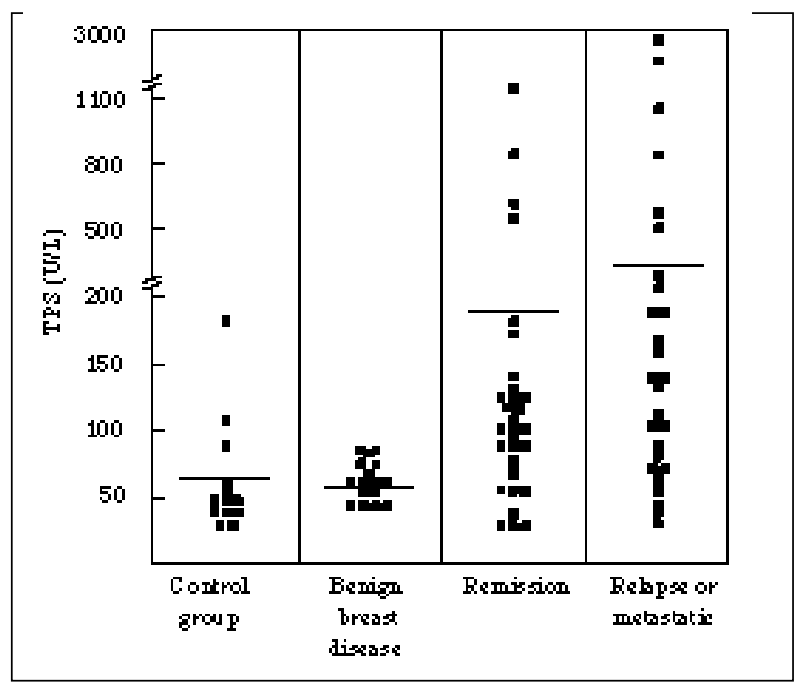

The mean levels of the four groups are shown in Table 1. The patients not in remission were found to have significantly higher levels of CA 15-3 (p<0.0001) and ceruloplasmin $(\mathrm{p}<0.0001)$ compared with the other three groups. Although the difference for TPS between the patients in remission and the patients with active breast cancer was not statistically significant $(p>0.05)$, both groups had higher levels than patients with BBD and healthy volunteers $(\mathrm{p}<0.01)$. All women in the four groups had serum CRP concentration within normal limits, that is, less than $6.0 \mathrm{mg} / \mathrm{l}$. There were positive correlations between the CA 15-3 and the serum ceruloplasmin levels $(\mathrm{r}=0.322 ; \mathrm{p}=0.002)$ and also between CA 15-3 and TPS levels $(\mathrm{r}=0.233 ; \mathrm{p}=0.027)$. There was not any correlation between ceruloplasmin and TPS $(r=0.200 ; p>0.05)$. 
Table 1

Mean (S.E.) CA 15-3, ceruloplasmin and TPS values in study groups

CA 15-3 (U/mL) Ceruloplasmin (mg/L) TPS (U/L)

\begin{tabular}{lllr}
\hline $\begin{array}{l}\text { Relapse or } \\
\text { metastatic }\end{array}$ & $121.8 \pm 25.0$ & $360.6 \pm 18.0$ & $325.9 \pm 110.4$ \\
& $(5.6-530.0)$ & $(271.2-707.6)$ & $(37.4-2760.0)$ \\
Remission & $21.0 \pm 2.8$ & $283.2 \pm 10.3$ & $184.0 \pm 48.7$ \\
& $(7.3-76.9)$ & $(221.1-409.6)$ & $(25.6-1133.0)$ \\
Benign breast & & & \\
disease & $17.9 \pm 1.7$ & $250.0 \pm 13.8$ & $58.9 \pm 3.4$ \\
& $(3.2-29.0)$ & $(167.8-375.0)$ & $(42.4-81.2)$ \\
Control group & $17.2 \pm 1.2$ & $249.9 \pm 22.6$ & $64.0 \pm 9.6$ \\
& $(10.3-29.4)$ & $(167.8-525.2)$ & $(34.4-181.0)$ \\
\hline
\end{tabular}

Table 2

CA 15-3, ceruloplasmin and TPS values in study groups

\begin{tabular}{|c|c|c|c|c|}
\hline Marker & $\begin{array}{c}\text { Sensitivity } \\
\%\end{array}$ & $\begin{array}{c}\text { Specificity } \\
\%\end{array}$ & $\begin{array}{l}\text { Positive } \\
\text { predictive } \\
\text { value } \\
\%\end{array}$ & $\begin{array}{r}\text { Negative } \\
\text { predictive } \\
\text { value } \\
\%\end{array}$ \\
\hline CA $15-3$ & 75.0 & 87.0 & 75.0 & 88.5 \\
\hline Ceruloplasmin & 75.0 & 74.1 & 56.7 & 86.7 \\
\hline TPS & 78.0 & 53.2 & 43.1 & 84.6 \\
\hline \multicolumn{5}{|l|}{ CA $15-3$ and/or } \\
\hline \multicolumn{5}{|l|}{ CA $15-3$ and/or } \\
\hline TPS & 100.0 & 48.3 & 46.6 & 100.0 \\
\hline \multicolumn{5}{|c|}{ Ceruloplasmin and/or } \\
\hline $\begin{array}{l}\text { TPS } \\
\text { CA 15-3 and/or }\end{array}$ & 96.4 & 41.9 & 42.8 & 96.2 \\
\hline \multicolumn{5}{|c|}{ Ceruloplasmin and/or } \\
\hline TPS & 100.0 & 43.5 & 44.4 & 100.0 \\
\hline
\end{tabular}

The cut-off levels (75\% - 78\% sensitivity) determined for each test were $25.0 \mathrm{U} / \mathrm{ml}$ for CA $15-3,285.0 \mathrm{mg} / \mathrm{l}$ for ceruloplasmin and $70.0 \mathrm{U} / \mathrm{l}$ for TPS. Using these cut-off levels, the positive predictive values for CA 15-3, ceruloplasmin and TPS were $75.0 \%, 56.7 \%, 43.1 \%$, respectively and negative predictive values were $88.5 \%$, $86.7 \%$, and $84.6 \%$, respectively. By the combined use of tumour markers the sensitivity for active breast cancer detection was increased. The results are summarised in Table 2. Two breast cancer patients in remission with elevated CA 15-3 and TPS levels developed active disease during the six-month follow up.

\section{DISCUSSION}

Clinical examination, mammography, fine needle aspiration biopsy and open surgical biopsy are established diagnostic methods in breast cancer and the final diagnosis of cancer should be based on histopathology(14). In breast cancer many tumour markers have been studied in the hope of finding a blood test for cancer, but none of them has had such sensitivity and specificity that it could replace conventional diagnostic methods(12). Tumour markers may be useful, along with other tests, in the assessment of the prognosis, monitoring response to treatment and the early detection of metastases $(9,11,15$ 17).

CA 15-3, the most commonly used tumour marker in breast cancer, was shown to be increased in $60 \%$ of patients with metastases whereas in patients without metastases, only about 30\% had increased levels. The principal application of CA 15-3 assay is for monitoring the course and therapeutic response of breast cancer $(4,18)$. In our study, we found higher levels of CA 15-3 in patients with active breast cancer compared to patients in remission, similar to other series $(14,18,19)$.

In a study by Schapira and Schapira (20), the ceruloplasmin levels were found to be elevated in $89 \%$ of 103 patients with breast carcinoma and then fell by $35 \%$ as soon as patients responded to treatment. They also showed that the ceruloplasmin levels of patients with breast carcinoma increased 16-34 weeks before their metastases became clinically overt. In our previous study, we suggested that ceruloplasmin could be used as a tumour marker for the follow up of breast cancer patients(21). In the present study, we again found serum ceruloplasmin levels valuable in detecting active breast cancer. Several clinical studies have been published on TPS determination in women with breast cancer. Elevated TPS serum levels are reported with frequencies varying between $31 \%$ and $71 \%(12,22,23)$. In our trial, we found elevated TPS serum levels in $78 \%$ of patients with active breast cancer patients.

The sensitivity of a tumour marker is the percentage of test results which are correctly positive in the presence of a tumour and it does not show the false positive results in the control groups, so it may be valuable in the monitoring of the response to treatment and the early detection of metastases or relapse in patients with histopathologically documented breast cancer. If the number of false negative cases are low, the negative predictive value which identify those individuals who truly do not have the disease among all individuals whose screening tests are negative would be high(4). Specificity and positive predictive values are more important in the detection of breast cancer and tumour markers are not applicable as screening tests at present $(2,25,26)$. As a result, a marker with high sensitivity and high negative predictive value would be the most suitable parameter for the follow up of patients in combination with other tests. There have been many attempts to use multivariate and discriminant analyses to improve the sensitivity and specificity of tumour markers. A variety of markers, each of which had been reported to be elevated in patients with cancer of the breast, were combined to see if multivariate analysis would yield information not available by the use of one marker alone(11,26-29). In this study, we examined the value of CA 15-3/ceruloplasmin/TPS panel in the monitoring of breast cancer and found that this panel increased the 
sensitivity and negative predictive value compared to the single marker tests (Table 2).

In conclusion, the combined use of tumour markers may be valuable in detecting relapse or metastases in breast cancer patients, although the use of the CA 15-3/ ceruloplasmin/TPS panel is not of practical value in screening because of its low specificity.

\section{REFERENCES}

1. Bates, S.E. and Longo, D.L. Tumour marker: value and limitation in the management of cancer patients. Cancer Treat. Rev. 1985;12: 163-207.

2. Hollinshead, A.C. Biological markers of breast cancer: A review. Cancer Invest., 1987; 5:581-591.

3. Duffy, M.J. New cancer markers. Ann. Clin. Biochem., 1989; 26:379-387.

4. Fateh-Maghadam, A., Steiber, P., and Seidel, D. Description of individual tumour markers. In: Sensible use of tumour markers; eds Fateh-Maghadam A, Steiber P, Seidel D. Editiones Roche, Basel, pp 33-49.,1993.

5. Gion, M., Barioli, P., and Mione, R. Tumor markers in breast cancer follow-up: A potentially useful parameter still definitive assessment. Ann. Oncol. 1995; 6: S31-S35.

6. Kanapuli, S.P., Singh, H., Singh, P., and Kumar, A. Ceruloplasmin gene expression in human cancer cells. Life Science, 1987; 40:22252228.

7. Hrgovcic, M., Tessmer, F., Thomas, F.B., Gambie, J.F., and Shullenberger, C.C. Serum copper observation in patients with malignant Lymphoma. Cancer, 1973; 6:1512-24.

8. Margerison, A.C.F., and Mann, J.R. Serum copper, serum ceruloplasmin, and erythrocyte sedimentation rate measurements in children with Hodgkin's disease, non-Hodgkin's lymphoma and non-malignant lymphadenopathy. Cancer 1985; 55: 1501-6.

9. Sinha, S.N., and Gabrieli, E.R.. Serum copper and zinc levels in various pathologic conditions. Amer. J. Clin. Path., 1970; 54: 570-7.

10. Zusman, I. Variability of serum tumor-associate antigens and their significance in cancer diagnosis (review). Oncol. Rep, 1994; 1: 997-1009.

11. Eskelinen, M., Hippelainen, M., and Salmela, E. A prospective study of tissue polypeptide specific antigen (TPS) in breast cancer diagnosis. Anticancer Res. 1992; 12:2033-2036.

12. Gion, M., Mione, and R., Gatti, K. Is tissue polypeptide antigen still a useful tumor marker in breast carcinoma? Comparison with CA 15-3 and MCA. Tumori 1990; 76: 360-364.

13. Pujol, J.L., Cooper, E.H., and Grenier, J. Clinical evaluation of serum tissue polypeptide-specific-antigen (TPS) in non-small cell lung cancer. Eur. J. Cancer, 1994; 30A: 1768-1774.
14. Jotti, G.S., and Bombardieri, E. Circulating tumor markers in breast cancer (review). Anticancer Res. 1990; 10: 253-258.

15. Hilkens, J., Buijs, F., Hageman, P.H., Calafat, J., Sonnenberg, A., and van Der Valk, M. Monoclonal antibodies against human milkfat globule membranes detecting differentiation antigens of the mammary gland and its tumors. Int. J. Cancer, 1984; 34:197-206.

16. Waalkes, T.P., Enterline, J.P., Shaper, J.H., Abeloff, M.D., and Ettinger, D.S. Biological marker for breast carcinoma. Cancer, 1984; 53: 664-671.

17. Stenman, U.K., and Heikkinen, R. Serum markers for breast cancer. Scand. J. Clin. Lab. Invest, 1991; 206p: 52-59.

18. Rousse, J., Tubiana-Hulin, M., and Fileul-Saint-Cloud, A. Breast cancer. In: Handbook of chemotherapy in clinical oncology; (Eds), Droz JP, Cvitcovic E, Armand JP and Khoury S. FIIS, Houston, pp 238-245, 1988.

19. Hayes, D.F., Zurawski, V.R., and Kufe, D.W. Comparison of circulation CA 15-3 and carcinoembryonic antigen levels in patients with breast cancer. J. Clin. Oncol. 1986; 4:1542-1550.

20. Schapira, D., and Schapira, M. Use of ceruloplasmin levels to monitor response to therapy and predict recurrence of breast cancer. Breast Cancer Res. Treat., 1983; 3:221-224.

21. Ozyilkan, O., Baltall, E., Ozyilkan, E., Tekuzman, G., Kars, A., and Firat, D. Ceruloplasmin level in women with breast disease: Preliminary results. Acta, Oncologica, 1992; 31:843-846.

22. Bjorklund, B., and Bjorklund, V. Antigenicity of pooled human malignant and normal tissues by cyto-immunological technique: Presence of insoluble, heat-labile tumour antigen.Int. Arch. Allergy 1957; 10: 153-184.

23. Mattson, W., and Borgstrom, S. Tissue Polypeptide Antigen as a Guide in Antineoplastic Treatment of Advanced Mammary Carcinoma. In: Proceeding of the Third International Symposium on Detection and Prevention of Cancer, New York, 1976; 579.

24. Smith, R.E. Biochemical detection of recurrent breast cancer. Cancer Detect Prevent. 1988; 11:303-309.

25. C Hayes D F., Gelman, R., Henderson I.C., and Kufe D.W. Comparison of CA 15-3 and carcinoembryonic antigen in monitoring the clinical course of patients with metastatic breast cancer. Cancer Res. 1988; 48:4107-4712

26. Barak, M., Steiner, M., Finkel, B., Abrahamson, J., Antal, S., and Gruener, N. CA 15-3, TPA and MCA as markers for breast cancer. Eur. J. Cancer, 1990; 26: 577-80.

27. Scwarz, M.K. Cancer markers. In: Cancer: Principles and practice of Oncology. DeVita VT, Hellman S, Rosenberg SA, eds J B Lippincott, Philadelphia, pp 531-542, 1993.

28. van Dalen, A. TPS in breast cancer - A comparative study with carcinoembryonic antigen and CA 15-3. Tumor Biol., 1992; 13: 10-17.

29. Bremer, K. Micus S Bremer, G. and Eberhard. A. A comparison of the clinical relevance of CEA, CA 15-3 and MCA in breast cancer. Onkologie. 1996; 19:170-174. 